\title{
Parametric Energy Simulations of a Nordic Detached House Heated by a Wood Stove
}

\author{
Martin Thalfeldt ${ }^{1,2^{*}}$, Anders Skare ${ }^{1}$, Laurent Georges ${ }^{1}$, and Øyvind Skreiberg $^{3}$ \\ ${ }^{1}$ Norwegian University of Science and Technology, Department of Energy and Process Engineering, Kolbjørn Hejes vei 1B, 7491 \\ Trondheim, Norway \\ ${ }^{2}$ Tallinn University of Technology, Department of Civil Engineering and Architecture, Ehitajate tee 5, 19086 Tallinn, Estonia \\ ${ }^{3}$ SINTEF Energy Research, Kolbjørn Hejes vei 1A, 7465 Trondheim, Norway
}

\begin{abstract}
Wood stoves are widely used in Nordic countries. They offer a good opportunity to use biomass for space-heating and to reduce the peak power of all-electric buildings. However, wood stoves are highly concentrated heat sources with limited control compared to other typical heat emission systems, which makes the assessment of their impact challenging. This study introduces a simulation-based parametric study of a detached house equipped with a wood stove located in Oslo, Norway. The respective impact of different building parameters and stove nominal powers on the building performance is illustrated. The analysis shows that the annual total space-heating needs (i.e. the sum of the base load, modelled as ideal heaters representing the electrical radiators, the stove and the heating of the ventilation supply air) increased significantly due to the higher average indoor temperature. The resulting heat emission efficiency of the stove ranged between $66 \%$ and $90 \%$. However, the stoves covered between $28 \%$ and $62 \%$ of the total spaceheating needs. When using the stove, the maximum hourly-averaged power for the electrical radiators decreased between $5 \mathrm{~W} / \mathrm{m}^{2}$ and $31 \mathrm{~W} / \mathrm{m}^{2}$ during the peak hours of the electricity grid. The building thermal mass, insulation level, as well as the combination of internal door position with the bedroom temperature setpoint, had a significant impact on the calculated values. Finally, the study revealed that the occupant behaviour modelling should be improved to better capture the wood stove impact on the energy performance using building simulations.
\end{abstract}

\section{Introduction}

Wood stoves are widely used and offer a good opportunity to use biomass for space-heating and reduce $\mathrm{CO}_{2}$ emissions. Kipping and Trømborg [1] studied 608 households in Norway and wood stoves were used in more than $90 \%$ of them. They showed that in more than half of the buildings with direct electric heating, wood stoves are the main source of heating according to the building users. It is common practice to assess the energy performance of buildings before construction and, as wood stoves are typical heating sources, their impact on the energy performance should be evaluated.

A main challenge to consider wood stove during design is that detailed building performance simulation (BPS) is required. Georges et al. [2, 3] conducted such investigations and showed that the proper integration of wood stoves in passive houses is possible, both in the mild climate of Belgium and cold climate zones of Norway. The use of BPS to evaluate the time-varying operative temperature during the space-heating using a stove has been validated experimentally [4, 5]. Unfortunately, these detailed simulations are not accessible when people (possibly assisted by wood stove dealers) have to select a stove for their home. Therefore, a simple but accurate enough method to assess the wood stove influence on the building energy performance is needed. Previous researches have shown the potential and limitations of standard BPS software for this application. However, none of the existing studies on the building integration of wood stoves have investigated the impact of the building insulation level as well as the combination of the wood stove with different heat emitters in the other rooms.

This study presents a parametric study of a detached house located in Oslo, Norway, with varying construction modes, insulation levels and stove nominal powers $\left(P_{n}\right)$. The aim is to give insight on the impact of wood stoves on the energy performance of a detached house. The stove heat emission efficiency and the fraction of the total space-heating needs covered by the stove are studied. In addition, the potential impact of the wood stove on the grid interaction is assessed. This study complements a study by Thalfeldt et al. [6] that proposed a simplified power sizing method for the correct building integration of wood stoves, which is based on assessment of thermal comfort.

* Corresponding author: martin.thalfeldt $@$ taltech.ee 


\section{Methods}

This study is based on annual simulations of a typical detached house in Norway in the location and climate of Oslo. Parametric simulations were done with various construction modes, insulation levels and stove nominal powers. Their impact on the heat balance of the building and the stove heat emission efficiency, as well as their influence on the peak power of the base heating system, were calculated. The detailed description of methods is given in the subsequent paragraphs. The simulation model, building structures and stoves are identical to the ones used in a previous study [6]. In addition, the cases included two positions for all the internal doors, fully open or closed, which were kept fixed during the yearly simulation. The selected temperature setpoints of bedrooms were either $16{ }^{\circ} \mathrm{C}$ or $20^{\circ} \mathrm{C}$, as this depicts the common habit in Norway to prefer colder bedrooms [7, 8].

\subsection{The simulation model of the detached house}

The simulations of the detached house were performed with the well-validated dynamic building performance simulation software IDA-ICE (version 5, beta 04) [9]. The main advantage of this version is its capability to accurately evaluate the mean radiant temperature at the location of the occupant as it models accurately radiative heat transfer between surfaces. The living room geometry has a L-shape and, in this new version, the stove geometry is directly integrated inside the virtual geometry of the room. The resulting geometry is therefore not convex and view factors between surfaces were computed numerically by IDA-ICE $[10,11]$.

The hourly profiles for the internal heat gain from occupants, equipment and artificial lighting were taken from ISO 17772-1 [12] and are given in Fig. 3. Balanced mechanical ventilation with heat recovery is implemented. A total airflow rate of about $208 \mathrm{~m}^{3} / \mathrm{h}$ was used, which complies with the minimum requirements of the Norwegian building regulation [13]. The cascade ventilation supplies air to the living room and bedrooms, while extracts air from the kitchen, bathrooms, the laundry room and the staircase.

Stoves with nominal power $\left(P_{n}\right)$ between 3 and 12 $\mathrm{kW}$ and with batch loads (here defined as the total energy emitted by the stove during one combustion cycle) ranging from 7.5 to $30 \mathrm{kWh} /$ cycle were used in the simulations. Fig. 4 illustrates the heat emission profiles of each stove. These profiles were obtained using a semi-empirical model of wood stoves called Fuelsim-Transient, developed by Skreiberg [14]. It models the combustion and heat transfer physics inside the stove.

In IDA-ICE, these heat emission profiles were given as an input to the stove model. Given realistic stove dimensions for each nominal capacity $\left(P_{n}\right)$, the resulting stove surface temperature is computed dynamically by IDA-ICE for each time step.
The following rule-based control algorithm for the operation of the stove and ideal heaters was implemented in IDA-ICE:

- A stove cycle was started when the operative temperature was lower than $20.1^{\circ} \mathrm{C}$ in the living room, if it was assumed occupied. The occupancy schedule in the living room was defined between 07:00-10:00 and 19:00-22:00 during weekdays, and between 07:00-22:00 during weekends.

- The room temperature setpoint for ideal heaters was 20 ${ }^{\circ} \mathrm{C}$ in all the rooms except bedrooms, where the temperature setpoint was $16^{\circ} \mathrm{C}$ or $20{ }^{\circ} \mathrm{C}$, depending on the case.

- The total heat emission of the stove, meaning the sum of convection and longwave thermal radiation, was imposed to the stove surface as a function of operation time from the start of the cycle according to the profiles provided in Fig. 4.

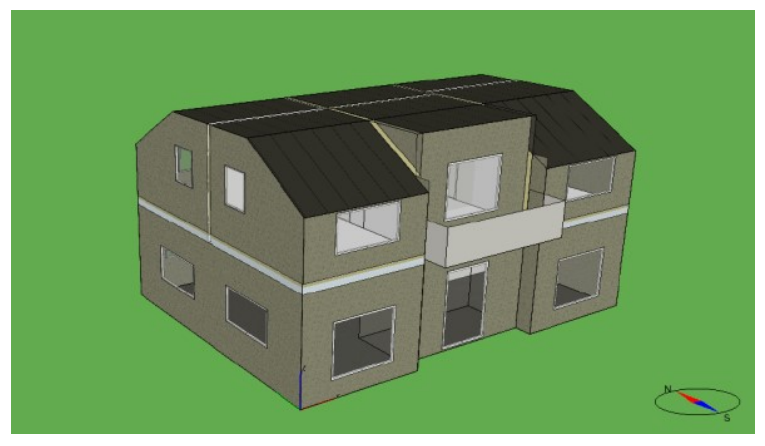

Fig. 1. 3D view of the virtual geometry of the detached house.

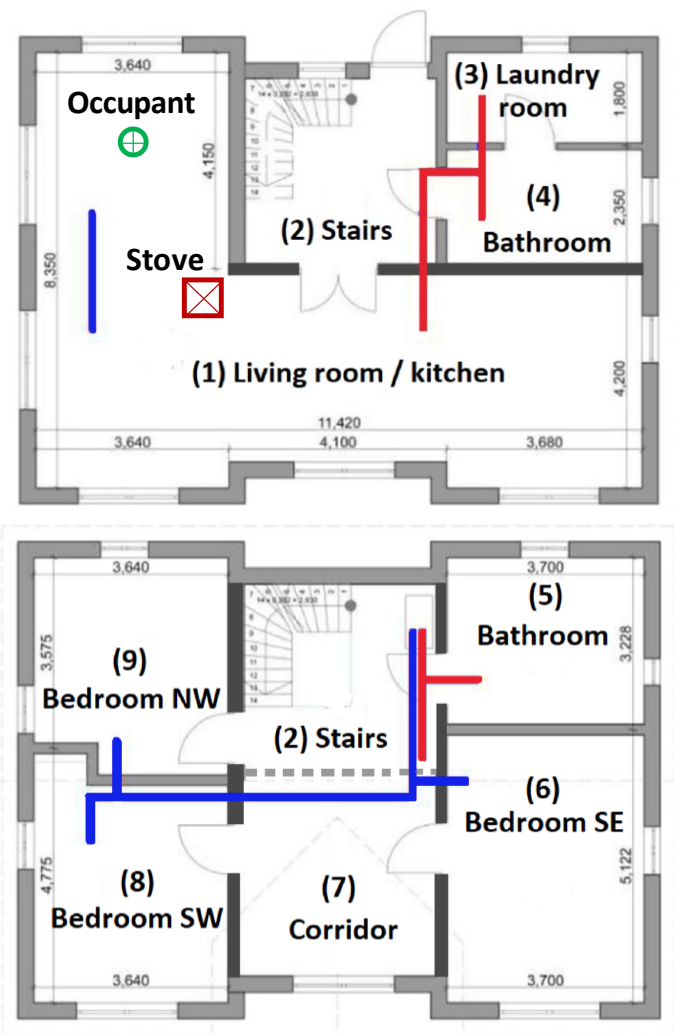

Fig. 2. Ground (top) and $1^{\text {st }}$ floor (bottom) plans of the detached house with the locations of the stove, occupant and mechanical ventilation supply (blue) and extract (red) air ducts. 


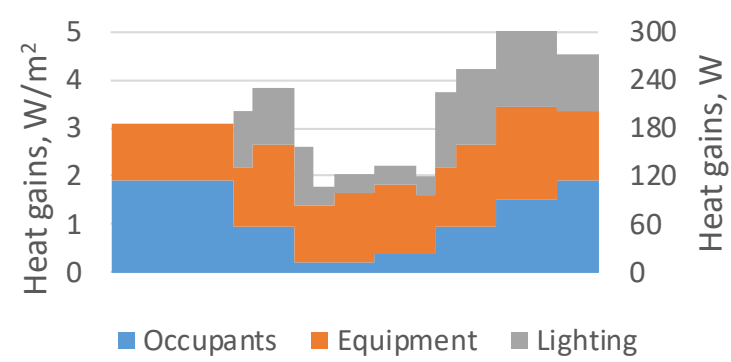

Fig. 3. The daily profile of the internal (sensible) heat gains from occupants, equipment and electrical lighting in all zones of the building model.

\subsection{The construction of the detached house}

The study included various insulation levels and construction modes (CM), see Table 1 and Table 2, respectively. The construction modes influence the thermal capacity of the building. The insulation level ranged from passive house $(\mathrm{PH})$ level to the Norwegian national requirements from 1987 (TEK87). The specific heat losses of cases TEK97 and TEK87 are significantly higher as they have natural ventilation. For the sake of simplicity, this is modelled as a mechanical ventilation without heat recovery and without pre-heating of the ventilation supply air. The ventilation losses by the stove combustion air are not modelled. The stove is assumed to have an independent air intake, which is the best practice for buildings with balanced ventilation.

The specific heat losses through internal constructions of the living room also depend on the construction mode (see Table 2). The effective thermal capacities were calculated according to EN ISO 52016$1: 2017$ [15] assuming that either $10 \mathrm{~cm}\left(C_{\text {eff }, 10}\right)$ or $2 \mathrm{~cm}$ $\left(C_{e f f, 2}\right)$ of the wall construction are activated during one stove cycle. The calculations of the specific heat losses and effective thermal capacity have been described in detail in [16].
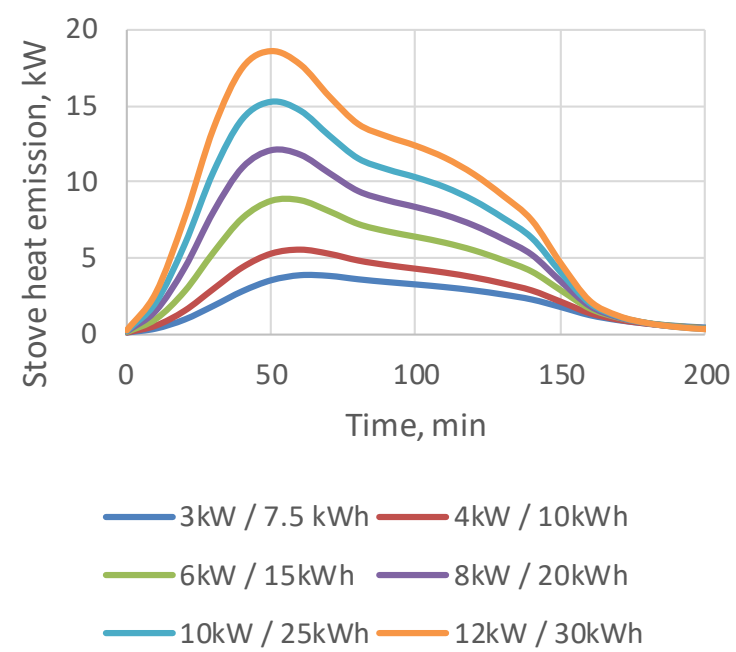

Fig. 4. The heat emission profiles for all wood stoves as a function of the stove nominal capacity and batch load.
Table 1. The specific heat loss through the living room exterior envelope $\left(U A_{e n v}\right)$ as function of thermal insulation level.

\begin{tabular}{|c|c|c|}
\hline Thermal insulation level & $\begin{array}{c}\text { UAenv, } \\
\text { W/K }\end{array}$ & Stove $P_{n}$ range, $\mathrm{kW}$ \\
\hline Passive house (PH) [17] & 31.5 & $3,4,6$ \\
\hline TEK10 [13] & 49.6 & $3,4,6$ \\
\hline TEK07 [18] & 56.1 & $4,6,8$ \\
\hline TEK97 [19] & 91.3 & $4,6,8,10$ \\
\hline TEK87 [20] & 118.0 & $6,8,10,12$ \\
\hline
\end{tabular}

Table 2. The calculated specific heat loss through the internal constructions $\left(U A_{\text {int }}\right)$ and thermal capacity $(C)$ of living rooms depending on the construction mode $(\mathrm{CM})$ and the thickness of effective activation depth, $10 \mathrm{~cm}\left(C_{\text {eff, } 10}\right)$ or $2 \mathrm{~cm}\left(C_{\text {eff, }, 2}\right)$.

\begin{tabular}{|c|c|c|c|c|}
\hline $\begin{array}{c}\text { Construction } \\
\text { mode }\end{array}$ & Description & $\begin{array}{c}\text { UA } \mathrm{W} / \mathrm{K}, \\
\mathrm{W}\end{array}$ & $\begin{array}{c}\mathrm{C}_{\text {eff, } 10,} \mathrm{kWh} / \mathrm{K} \\
\mathrm{CM} 1\end{array}$ & $\begin{array}{c}\mathrm{C}_{\text {eff, }, 2}, \\
\mathrm{kWh} / \mathrm{K}\end{array}$ \\
\hline $\mathrm{CM} 2$ & $\begin{array}{c}\text { Mixonry } \\
\text { masonood }\end{array}$ & 187.0 & 7.94 & 1.48 \\
\hline $\mathrm{CM} 3$ & $\begin{array}{c}\text { Wooden } \\
\text { heavy }\end{array}$ & 76.5 & 3.45 & 1.07 \\
\hline $\mathrm{CM} 4$ & Masonry light & 41.8 & 2.57 & 0.99 \\
\hline $\mathrm{CM} 5$ & Wooden light & 25.1 & 1.77 & 1.02 \\
\hline
\end{tabular}

\subsection{Stove performance indicators}

The following indicators were used to rate the performance of the heating system:

- emission efficiency of the stove,

- stove fraction in the total space-heating needs,

- duration of the periods when the operative temperature exceeded $25^{\circ} \mathrm{C}$ during the space-heating season, - the maximum power of the base heating system (ideal heaters) during the peak hours of the electricity grid.

In this study, the emission efficiency of the stove is calculated for each case by comparing the total spaceheating needs between two different simulations: with and without the stove (i.e. the reference case). The emission efficiency $\eta_{\text {emission }}$ is calculated according to equation 1.

$$
\eta_{\text {emission }}=\frac{\left(Q_{S H, \text { ref }}+Q_{A H U, r e f}\right)-\left(Q_{S H, i}+Q_{A H U, i}\right)}{Q_{s t o v e, i}}
$$

where $Q_{S H}$ is the energy needs of ideal heaters [kWh], $Q_{A H U}$ is the energy needs for supply air heating $[\mathrm{kWh}], Q_{\text {stove }}$ is the energy needs of the stove $[\mathrm{kWh}]$, while the subscripts ref and $i$ denote the reference case and the case $i$, respectively. Typically, the emission efficiency of a heating system is calculated by comparing cases with identical indoor temperature setpoints. However, in this study, there is a $0.1{ }^{\circ} \mathrm{C}$ 
difference between the setpoint for the ideal heaters and for the stove in order to ensure the priority of the stove operation over the ideal heaters in the living room.

For each case, the stove fraction in the total spaceheating needs of the building is calculated. Again, the total heating needs consist of ideal heaters, the stove and supply air heating. In addition, the annual number of stove cycles are reported for each case.

The over-heating was assessed based on the accumulated duration of the periods when the living room operative temperature exceeded $25^{\circ} \mathrm{C}$ during the space-heating season. A temperature threshold of $25^{\circ} \mathrm{C}$ was selected based on the standard EN 16798-1:2019 [21]. The heating season was selected based on a qualitative assessment of the annual hourly spaceheating power profiles of the reference cases. In most cases, the heating season was from October $1^{\text {st }}$ to May $1^{\text {st }}$, with the exception of the passive house level, which had a shorter period, from October $15^{\text {th }}$ to April $15^{\text {th }}$.

The impact of the stove on the electricity grid was assessed based on the maximum hourly-averaged power of the ideal heaters during the peak hours of the grid. According to Kipping and Trømborg [1], direct electric heating is clearly the dominating heating strategy in Norway. Therefore, the peak power of ideal heaters can be used as they behave similarly to electric radiators. The peak hours of the grid were defined between 7:00 and 10:00 and 17:00-20:00, which are the same hours as in the study by Clau $\beta$ and Georges [22].

\section{Results}

For the sake of conciseness, only the results of the following cases are presented:

- CM1/OD/16: construction mode 1, open internal doors and bedroom temperature setpoint of $16^{\circ} \mathrm{C}$.

- CM5/OD/16: construction mode 5, open internal doors and bedroom temperature setpoint of $16^{\circ} \mathrm{C}$.

- CM5/CD/20: construction mode 5, closed internal doors and bedroom temperature setpoint of $20^{\circ} \mathrm{C}$.

The case CM5/OD/16 was assumed to represent the typical situation in Norway, meaning a detached house with wooden construction and a lower bedroom temperature setpoint of $16^{\circ} \mathrm{C}$. The comparison of cases $\mathrm{CM} 1 / \mathrm{OD} / 16$ and $\mathrm{CM} 5 / \mathrm{OD} / 16$ enables to assess the impact of the thermal mass and the insulation level of partition walls. The comparison of cases CM5/OD/16 and $\mathrm{CM} 5 / \mathrm{CD} / 20$ enables to assess the combination of the impact of internal door position and the bedroom temperature setpoint.

\subsection{Heat balance of the building}

An example of the impact of the stove on the living room temperature is illustrated in Fig. 5, which presents the temperature fluctuations during January $11^{\text {th }}$ and $12^{\text {th }}$ in the passive house using CM1/OD/16 and CM5/OD/16 cases. The figure includes the cases with a stove $P_{n}$ of $3 \mathrm{~kW}$ and $6 \mathrm{~kW}$, and their respective reference cases. Both days had average outdoor temperature of $-5^{\circ} \mathrm{C}$, but January $11^{\text {th }}$ was cloudy and January $12^{\text {th }}$ sunny, which is reflected by the temperature increases in the middle of January $12^{\text {th }}$. The temperature increases in the morning and the evening indicate that the stove was activated by the control algorithm, whereas the room temperature of the reference cases was relatively stable. The higher temperatures due to the stove increased the space heating needs. The building characteristics and the stove $P_{n}$ influenced how often the stove was activated. In most cases with a stove, the stove was not activated in the evening of January $12^{\text {th }}$, only in the morning. The only exception was the case with heavy construction (CM1) and stove $P_{n}$ of $3 \mathrm{~kW}$, in which the stove was activated also in the evening of January $12^{\text {th }}$.

The impact of the wood stove on the space-heating needs of the various cases in comparison to their reference cases without stove are given in Fig. 6.

With open internal doors and a bedroom temperature setpoint of $16{ }^{\circ} \mathrm{C}(\mathrm{OD} / 16)$, the heat emission efficiency of the stove with the heaviest construction mode (CM1) varied between $87 \%$ and $90 \%$. There was only a slight decrease of the emission efficiency when the stove nominal power increased. The heat emission efficiency of the wood stove with the lightest construction mode (CM5) was significantly lower and ranged between 73\% and $84 \%$. With closed internal doors and a bedroom temperature setpoint of $20{ }^{\circ} \mathrm{C}(\mathrm{CM} 5 / \mathrm{CD} / 20)$, the stove heat emission efficiency further decreased up to $7 \%$. Regarding the influence of the building insulation, the less insulated buildings (i.e. TEK07 and TEK87) had lower stove emission efficiencies. The most efficient wood stoves currently available in the market have a generation efficiency of $\sim 85 \%$. Assuming this value leads to an overall efficiency of the wood stove ranging from $55 \%$ to $77 \%$ compared to ideal heaters.

The stove contribution to the total space-heating needs varied between $28 \%$ and $62 \%$. In contrast with the stove emission efficiency, these values depended less on the construction mode (based on the comparison the cases CM1/OD/16 and CM5/OD/16). Only the passive house cases gave differences larger than $1 \%$ for the stove nominal powers of 3 and $6 \mathrm{~kW}$. Both cases gave a difference of $4 \%$, but in the opposite direction. This might be explained by the fact that the cases with a stove nominal power of $3 \mathrm{~kW}$ had a similar annual number of stove cycles - 224 (CM1) and 230 (CM5).

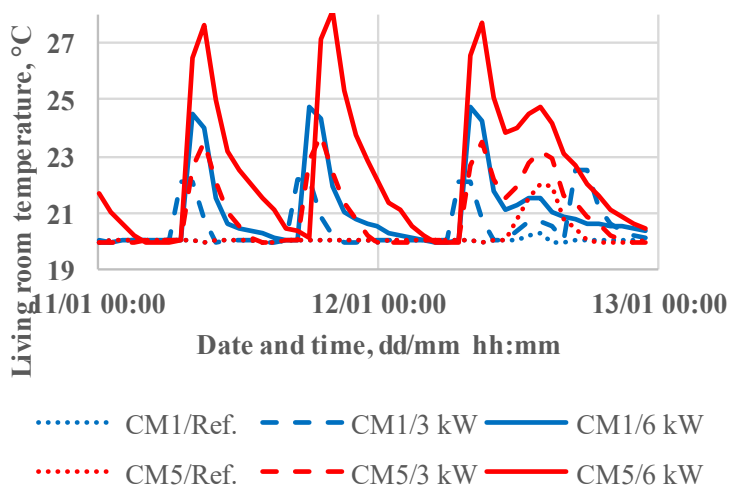

Fig. 5. The living room hourly average temperatures of cases $\mathrm{CM} 1 / \mathrm{OD} / 16$ and CM5/OD/16 with passive house insulation level. 

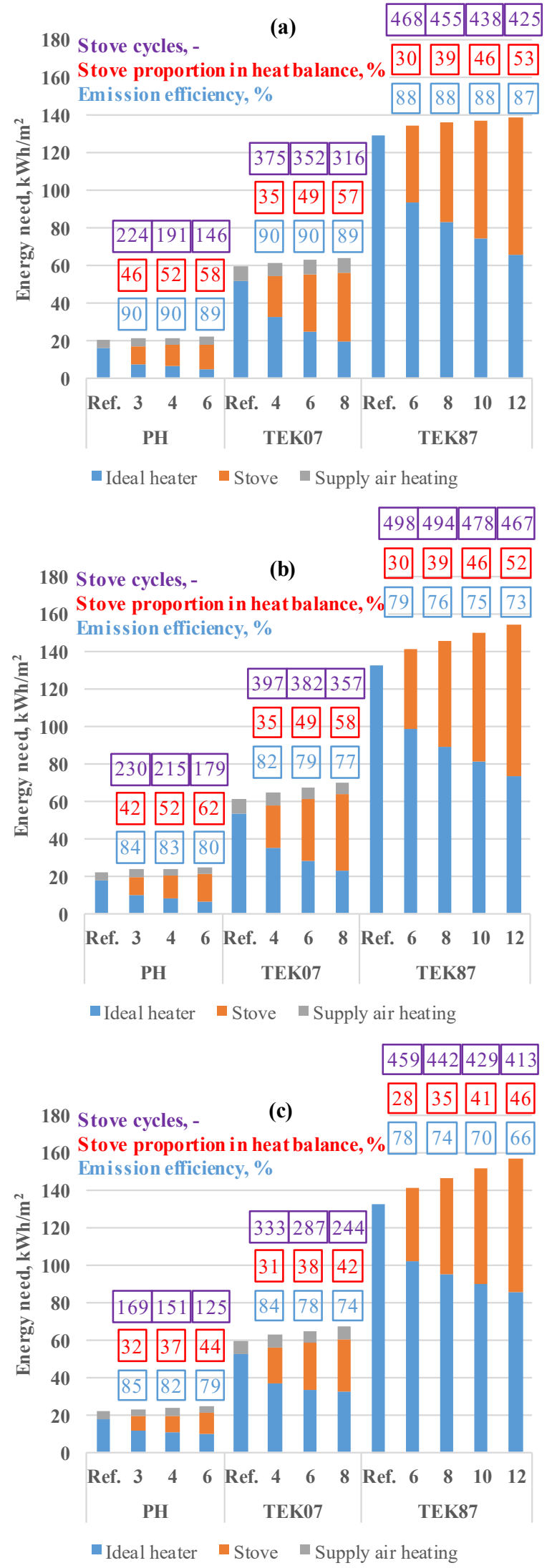

Fig. 6. The heat balance of the building distributed between ideal heaters, the stove and supply air heating and the stove emission efficiency, stove proportion in the heat balance and annual number of stove combustion cycles of cases $\mathrm{CM} 1 / \mathrm{OD} / 16$ (a), CM5/OD/16 (b) and CM5/CD/20 (c).
However, the case with stove nominal power of 6 $\mathrm{kW}$ and lighter constructions had a significantly smaller number of stove cycles - 146 (CM1) vs. 179 (CM5). The larger time constant of the building with heavier construction kept a more stable temperature and the stove was activated less by the control algorithm. The position of internal doors and the bedroom temperature setpoint had a larger impact on the stove fraction in the heat balance. The differences for the cases CM5/OD/16 and $\mathrm{CM} 5 / \mathrm{CD} / 20$ ranged between $2 \%$ and $18 \%$, whereas the difference was larger with larger stove nominal power.

The annual number of stove cycles ranged between 125 and 498. In reality, the higher number of cycles $(\sim 500)$ cannot really be expected as the actual user habits to operate the stove would most probably be different. This shows that the values obtained in this study are only indicative.
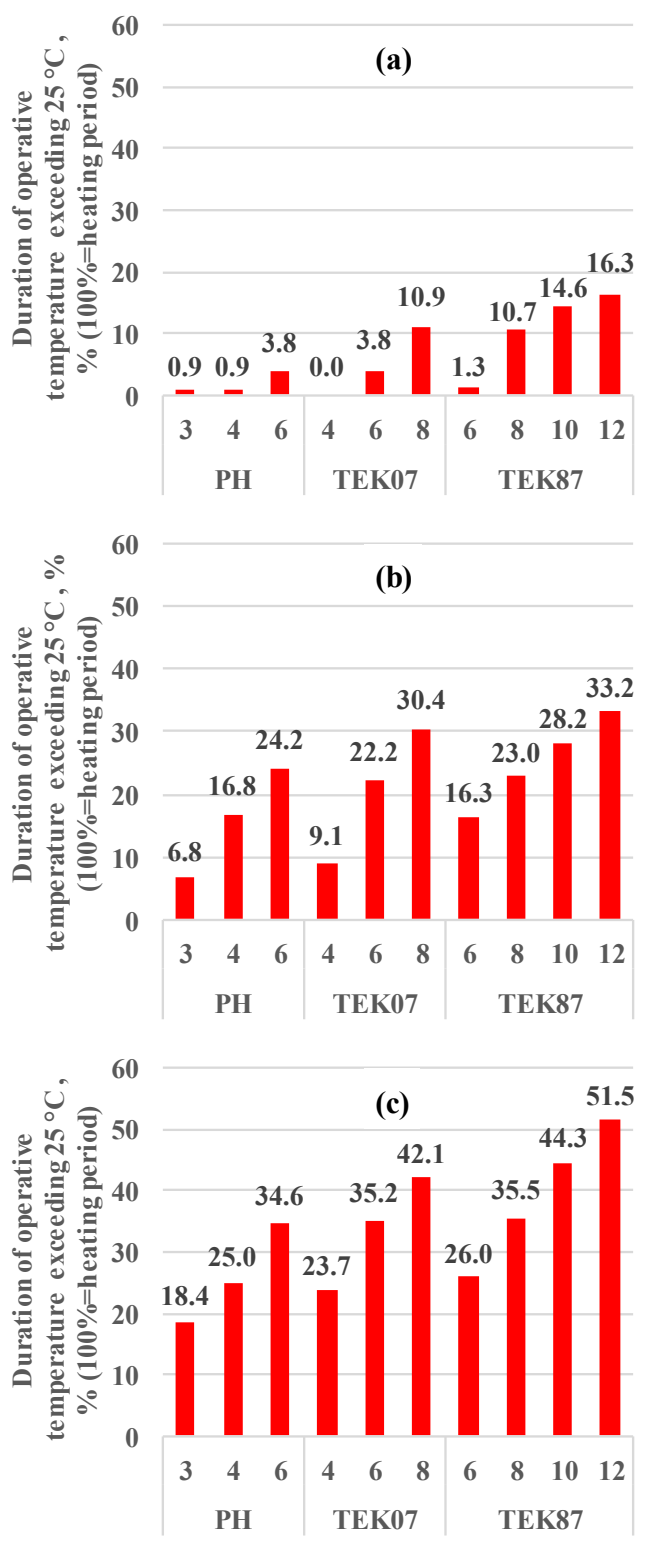

Fig. 7. Cumulated duration when the living room operative temperature is above $25^{\circ} \mathrm{C}$ during the heating season for cases $\mathrm{CM} 1 / \mathrm{OD} / 16$ (a), CM5/OD/16 (b) and CM5/CD/20 (c). 


\subsection{Over-heating of the living room}

The results for over-heating are presented in Fig. 7. The cumulated duration when the operative temperature exceeded $25^{\circ} \mathrm{C}$ during the space-heating season depended significantly on all the parameters included in this study. The building construction mode had the highest impact, which was followed by the position of internal doors and then stove nominal power.

The cases with the heaviest construction (CM1) had the lowest values, which ranged between $0.0 \%$ and $16.3 \%$. The corresponding cases with the lightest constructions (CM5) had values between $6.8 \%$ and $33.2 \%$. Assuming closed doors and bedroom temperature setpoint of $20{ }^{\circ} \mathrm{C}$, it further increased the values ranging from $18.4 \%$ to $51.5 \%$.

Higher stove $P_{n}$ increased the duration of hours above $25^{\circ} \mathrm{C}$ significantly. The largest increase was for CM5/CD/20 TEK87 insulation level, which doubled the over-heating duration from $26.0 \%$ to $51.5 \%$ if the stove $P_{n}$ increased from $6 \mathrm{~kW}$ to $12 \mathrm{~kW}$. The CM5/OD/16 with passive house insulation level was the only case with over-heating duration below $5 \%$. In that case the duration increased from $0.9 \%$ to $3.6 \%$, if the stove $P_{n}$ increased from $3 \mathrm{~kW}$ to $6 \mathrm{~kW}$.

The impact of the insulation level is assessed comparing cases with a $P_{n}$ of $6 \mathrm{~kW}$ for all the insulation levels. In case of the heaviest constructions (CM1), the overheating duration decreased from $3.8 \%$ to $1.3 \%$ for the passive house and TEK87 insulation levels, respectively. The respective values were $24.2 \%$ and $16.3 \%$ for the case CM5/OD/16 and $34.6 \%$ and $26.0 \%$ for the case $\mathrm{CM} 5 / \mathrm{CD} / 16$.

The large duration when operative temperature exceeded $25^{\circ} \mathrm{C}$ is caused by the relatively large batch sizes used in this study. Presumably, people would adjust the amount of wood they burn in their wood stove based on the weather conditions. Therefore, the control algorithm used in this study probably does not depict accurately the actual habits of occupants.

Carvalho et al. [23] measured daily variations of the living room temperature of up to $10^{\circ} \mathrm{C}$ during the heating season in a low-energy house heated by a wood stove in Denmark. Therefore, the occupants' preferences on the thermal comfort assumed in the standard EN 16798-1:2019 might not be valid when studying wood stoves. Seemingly, wood stoves would then cause significant over-heating in old detached houses (TEK87). However, in reality, wood stoves are often installed and used in these buildings, which indicates that there is no significant dissatisfaction with the thermal indoor environment due to over-heating caused by the wood stoves.

\subsection{Stove impact on the grid during peak hours}

The impact of the wood stoves on the peak load of electric heaters is presented in Fig. 8. The maximum hourly-averaged power of ideal heaters during the grid peak hours of the reference cases was in the range of 12$14 \mathrm{~W} / \mathrm{m}^{2}, 29-31 \mathrm{~W} / \mathrm{m}^{2}$ and $62-65 \mathrm{~W} / \mathrm{m}^{2}$ for insulation levels of the passive house, TEK07 and TEK87, respectively. Including a wood stove in the simulation models decreased these peak powers by $5-31 \mathrm{~W} / \mathrm{m}^{2}$ in comparison with the respective reference cases for all insulation levels and the relative decrease was between $32 \%$ and $56 \%$.

The peak power values obtained for the corresponding reference cases of $\mathrm{CM} 5 / \mathrm{OD} / 16$ and $\mathrm{CM} 5 / \mathrm{CD} / 20$ were relatively similar. The difference between the corresponding reference cases without a stove and those with a stove was smallest for low stove nominal powers. However, the peak power reduction due to a stove was significantly larger with open doors and bedroom temperature setpoint of $16^{\circ} \mathrm{C}$ in comparison with cases with closed internal door and bedroom temperature setpoint of $20^{\circ} \mathrm{C}$.

The impact of the construction mode on the peak power reduction was significantly larger than the position of doors and bedroom temperature. The differences between the peak power values of corresponding cases on CM1/OD/16 and CM5/OD/16 ranged between $1.6 \mathrm{~W} / \mathrm{m}^{2}$ and $5.1 \mathrm{~W} / \mathrm{m}^{2}$. The largest differences between corresponding cases were observed for cases with the lowest insulation level, i.e. TEK87.
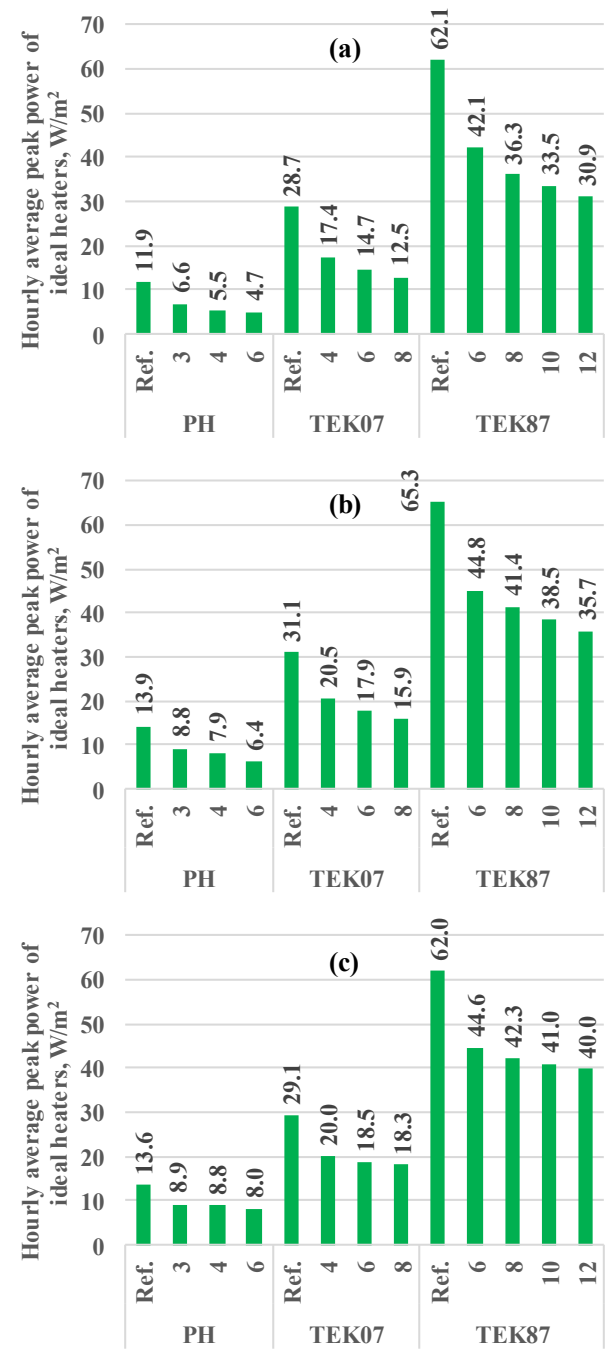

Fig. 8. The maximum hourly-averaged power of ideal heaters during 7:00-10:00 and 17:00-20:00 for cases CM1/OD/16 (a), $\mathrm{CM} 5 / \mathrm{OD} / 16$ (b) and CM5/CD/20 (c). 


\section{Discussion and conclusions}

This study analysed the impact of wood stoves on the performance of a detached house located in Oslo, Norway. A simulation-based parametric study with varying thermal mass, insulation level, internal door positions, bedroom temperature setpoint and stove nominal power was conducted. The stove heat emission efficiency, stove fraction of the total space-heating needs, the operative temperature in the living room (with the wood stove) and maximum hourly-averaged spaceheating power of the ideal heaters was assessed.

The assumptions about occupant behaviour and their preferences had a strong impact on the results of the annual simulations. Firstly, the stove operation was controlled only according to the operative temperature in the living room and fixed occupancy time schedules. During the preparation of this study, spontaneous conversations with people who have wood stoves in their houses were held. They pointed out that outdoor conditions (e.g. temperature and solar radiation) or other behavioural patterns might have a significant impact on the periods when their stove is operated.

Secondly, the same heat emission profiles of stoves were assumed each time the stove was operated. It is probable that people adjust the amount of wood they use per batch depending on the conditions. This eventually influences the heat emission profiles. Therefore, the results of this study are indicative and an improved occupant behaviour model for the manual operation of the wood stoves is needed to better represent the actual situation. In addition, a better understanding of people's preferences on the thermal indoor environment in buildings heated by a wood stove are needed to assess the perceived thermal comfort. Let also mention that the wood stoves considered in this study have limited heat storage capacity.

Thirdly, the ventilation losses generated by the combustion air of the stove in buildings with natural ventilation were not taken into account. This will further decrease the efficiency of the stove and will require a dedicated modelling in further studies.

Regardless of the modelling limitations of the stove operation, this study showed that wood stoves can have a significant impact on the energy performance a detached house. The wood stoves covered $28-62 \%$ of the total space-heating needs of the building, whereas these total needs increased significantly due to the higher indoor temperatures. This is characterized by a stove heat emission efficiency which varied between $66 \%$ and $90 \%$. This study also showed that the stoves may have a significant positive impact on the grid peak load of detached houses heated by electricity. The reduction of the maximum hourly-averaged power of the ideal heaters during the grid peak hours was between $5 \mathrm{~W} / \mathrm{m}^{2}$ and $31 \mathrm{~W} / \mathrm{m}^{2}$. In conclusion, all the variables (meaning the construction mode, insulation level, stove nominal power as well as the combination of the door position and bedroom temperature setpoint) had a significant impact on the calculated values.
The authors acknowledge the financial support by the Research Council of Norway and a number of industrial partners through the WoodCFD project ("Clean and efficient wood stoves through improved batch combustion models and CFD modelling approaches"), 243752/E20 as well as the European Regional Development Fund and the programme Mobilitas Pluss (Grant No - 2014-2020.4.01.16-0024, MOBTP88).

\section{References}

1. A. Kipping and E. Trømborg, Energy 93, 655-671 (2015).

2. L. Georges, Ø. Skreiberg, and V. Novakovic, Energy and Buildings 59, 203-213 (2013).

3. L. Georges, Ø. Skreiberg, and V. Novakovic, Energy and Buildings 72, 87-95 (2014).

4. L. Georges and Ø. Skreiberg, Journal of Building Performance Simulation 9(6), 663-679 (2016).

5. M. Thalfeldt, L. Georges, and Ø. Skreiberg,. Springer Proceedings in Energy Proceedings of Cold Climate HVAC Conference 2018, 653-663 (2018).

6. M. Thalfeldt et al., E3S Web of Conferences 111, 02066 (2019).

7. M. Berge, J. Thomsen, and H. M. Mathisen, Journal of Housing and Built Environment 32(2), 211-230 (2017).

8. B. Bjorvatn et al., Sleep Medicine 32, 157-161 (2017).

9. EQUA, 2014. [Online]. Available: http://www.equasolutions.co.uk/en/software/idaice.

10. L. Eriksson et al., Proceedings of the First Building Simulation and Optimization Conference, 2012, 149156.

11. L. Georges et al., Building and Environment 149, 169-181 (2019).

12. ISO 17772-1 (2017).

13. Forskrift om teknisk krav til byggverk (Byggetknisk forskrift TEK10) (2010).

14. Ø. Skreiberg, Fuelsim-Transient: A Mass, Volume and Energy Balance Spreadsheet for Batch Combustion Applications, NTNU, Trondheim, 2002.

15. EN ISO 52016-1:2017 (2017).

16. A. Skare, Validation of a method to select the optimal nominal power of a wood stove in residential buildings, NTNU (2018).

17. NS3700:2013 (2013).

18. Tekniske forskrifter til plan- og bygningsloven 2007 (TEK07) (2007).

19. Ren veiledning til teknisk forskrift til plan- og bygningsloven 1997 (TEK97) (1997).

20. Byggeforskrift 1987 (TEK87) (1985).

21. EN 16798-1:2019 (2019).

22. J. Clauß and L. Georges, Applied Energy 255, 113847 (2019).

23. R. L. Carvalho et al., Energy and Buildings 59, 244251 (2013) 